\title{
Perinatal mortality and congenital anomalies in babies of women with type 1 or type 2 diabetes in England, Wales, and Northern Ireland: population based study
}

Mary C M Macintosh, Kate M Fleming, Jaron A Bailey, Pat Doyle, Jo Modder, Dominique Acolet, Shona Golightly, Alison Miller

\begin{abstract}
Objective To provide perinatal mortality and congenital anomaly rates for babies born to women with type 1 or type 2 diabetes in England, Wales, and Northern Ireland.

Design National population based pregnancy cohort. Setting 231 maternity units in England, Wales, and Northern Ireland.

Participants 2359 pregnancies to women with type 1 or type 2 diabetes who delivered between 1 March 2002 and 28 February 2003.

Main outcome measures Stillbirth rates; perinatal and neonatal mortality; prevalence of congenital anomalies. Results Of 2359 women with diabetes, 652 had type 2 diabetes and 1707 had type 1 diabetes. Women with type 2 diabetes were more likely to come from a Black, Asian, or other ethnic minority group (type 2, 48.8\%; type 1,9.1\%) and from a deprived area (type 2, 46.3\% in most deprived fifth; type 1, $22.8 \%$ ). Perinatal mortality in babies of women with diabetes was $31.8 / 1000$ births. Perinatal mortality was comparable in babies of women with type 1 (31.7/1000 births) and type 2 diabetes $(32.3 / 1000)$ and was nearly four times higher than that in the general maternity population. 141 major congenital anomalies were confirmed in 109 offspring. The prevalence of major congenital anomaly was $46 / 1000$ births in women with diabetes (48/1000 births for type 1 diabetes; 43/1000 for type 2 diabetes), more than double that expected. This increase was driven by anomalies of the nervous system, notably neural tube defects (4.2-fold), and congenital heart disease (3.4-fold). Anomalies in 71/109 (65\%) offspring were diagnosed antenatally. Congenital heart disease was diagnosed antenatally in 23/42 (54.8\%) offspring; anomalies other than congenital heart disease were diagnosed antenatally in 48/67 (71.6\%) offspring.

Conclusion Perinatal mortality and prevalence of congenital anomalies are high in the babies of women with type 1 or type 2 diabetes. The rates do not seem to differ between the two types of diabetes.
\end{abstract}

\section{Introduction}

Pregnancy in women with diabetes is associated with an increased risk of congenital anomaly, perinatal morbidity, and mortality in their offspring. These risks have been evaluated predominantly in women with type 1 diabetes. ${ }^{1-4}$ The demographic pattern of diabetes is changing; increasing numbers of young people are being diagnosed as having type 1 diabetes, and the number of people diagnosed as having type 2 diabetes is increasing, predominantly among people in Black, Asian, or other ethnic minority groups. ${ }^{5}{ }^{6}$ Regional studies in the United Kingdom in the 1990s had indicated raised perinatal mortality among women with diabetes. ${ }^{48}$ Responding to this, the Confidential Enquiry into Maternal and Child Health (CEMACH) initiated a programme to assess the quality of maternity care and to examine pregnancy outcomes for women with diabetes in England, Wales, and Northern Ireland. Further information on this programme can be found in the CEMACH report. ${ }^{9}{ }^{10}$ Here we present perinatal mortality and congenital anomaly rates in the offspring of women with type 1 or type 2 diabetes, born between 1 March 2002 and 28 February 2003.

\section{Methods}

We defined pre-gestational diabetes as either type 1 or type 2 diabetes that had been diagnosed at least one year before the woman's estimated delivery date. We excluded the group, usually with type 2 diabetes, who present during pregnancy but in whom the diagnosis cannot be confirmed until after pregnancy. This ensured as homogenous a group as possible for the evaluation of mortality.

Health professionals at each maternity unit filled in a notification form and questionnaire for every woman who met the criteria for pre-gestational diabetes who delivered between 1 March 2002 and 28 February 2003 in England, Wales, and Northern Ireland. The CEMACH data collection included births to women resident in the Channel Islands and Isle of Man. The questionnaire covered demographic characteristics, type of diabetes, glycaemic control measurements, care from prepregnancy to the neonatal period, and outcome details up to day 28 for the baby. CEMACH regional managers coordinated data collection, validation of data, and entry on to a database.

All health professionals in England, Wales, and Northern Ireland are required to take part in confidential inquiry programmes; 231 units participated, and 2621 pregnancies were notified during the study period. We report on 2359 pregnancies; we excluded 262 pregnancies that resulted in miscarriage at less than 20 weeks of gestation or termination of pregnancy for indications other than congenital anomaly.

Two extra tables are on bmj.com 
Table 1 Gestation at delivery by outcome

\begin{tabular}{|c|c|c|c|c|c|c|c|c|}
\hline $\begin{array}{l}\text { Gestation at } \\
\text { delivery } \\
\text { (completed } \\
\text { weeks) }\end{array}$ & $\begin{array}{c}\text { Termination of } \\
\text { pregnancy for } \\
\text { congenital anomaly }\end{array}$ & $\begin{array}{l}\text { Late fetal loss or } \\
\text { stillbirth and } \\
\text { normally formed }\end{array}$ & $\begin{array}{l}\text { Late fetal loss or } \\
\text { stillbirth and } \\
\text { congenital anomaly }\end{array}$ & $\begin{array}{l}\text { Neonatal death } \\
\text { and normally } \\
\text { formed }\end{array}$ & $\begin{array}{l}\text { Neonatal death } \\
\text { and congenital } \\
\text { anomaly }\end{array}$ & $\begin{array}{l}\text { Alive at day } 28 \text { and } \\
\text { normally formed }\end{array}$ & $\begin{array}{c}\text { Alive at day } 28 \\
\text { and congenital } \\
\text { anomaly }\end{array}$ & Total \\
\hline$<20$ & 13 & - & - & - & - & - & - & 13 \\
\hline 20 to 23 & 17 & 12 & 2 & 2 & 0 & 0 & 0 & 33 \\
\hline 24 to 27 & 4 & 9 & 1 & 5 & 1 & 17 & 1 & 38 \\
\hline 28 to 31 & 0 & 11 & 0 & 1 & 1 & 70 & 5 & 88 \\
\hline 32 to 36 & 1 & 19 & 4 & 2 & 6 & 718 & 25 & 775 \\
\hline 37 to 40 & 0 & 13 & 2 & 1 & 2 & 1406 & 24 & 1448 \\
\hline$\geq 41$ & 0 & 0 & 0 & 0 & 0 & 5 & 0 & 5 \\
\hline Total & 35 & 64 & 9 & 11 & 10 & 2216 & 55 & 2400 \\
\hline
\end{tabular}

\section{Deprivation}

We explored the relation between diabetes in pregnancy and deprivation by applying an index of multiple deprivation score. ${ }^{11}$ As this measure applies only to England, we excluded women resident in Wales and Northern Ireland from this exercise.

\section{Perinatal and neonatal mortality}

We defined stillbirth as a fetal loss delivered after 24 completed weeks of gestation, neonatal death as the death of a live birth up to 28 days after birth, and perinatal death as a stillbirth or postnatal death up to seven days after birth. We compared perinatal mortality with national mortality data from the CEMACH 2002 perinatal death notifications and the Office for National Statistics. ${ }^{12}$

\section{Congenital anomalies}

We collected data on presumed congenital anomalies for live births antenatally and up to 28 days of life, for fetal losses after 20 completed weeks of gestation, and for terminations of pregnancy at any gestation. We confirmed the reported diagnoses by postmortem findings, genetic results, or correspondence. We coded confirmed anomalies according to the ICD-10 (international classification of diseases, 10th revision) and grouped them according to the classification system used by the European Surveillance of Congenital Anomalies (EUROCAT) (table A on bmj.com). We excluded minor anomalies (table B on bmj.com). We calculated the congenital anomaly rate as the number of offspring with one or more major anomalies divided by the number of live births and stillbirths. ${ }^{13}$ Offspring included fetal losses after 20 weeks' gestation and terminations of pregnancy at any gestation.

We compared the observed numbers of major congenital anomalies in the cohort with expected numbers based on age specific rates for 2002 reported to EUROCAT, adjusted for the maternal age distribution of the women in our study (personal communication, EUROCAT 2005). To allow for the higher prevalence of neural tube defects in the UK, we also calculated an expected figure for neural tube defects on the basis of the EUROCAT data originating only from Wales and six local registries in England.

We used Stata 8.0 for analyses. We used the Poisson distribution to obtain exact $95 \%$ confidence intervals for the rate and prevalence ratios. ${ }^{14}$

\section{Results}

All maternity units in England, Wales, and Northern Ireland delivering care to women with diabetes participated. Although we had no measure of the completeness of reporting within individual units, the observed prevalence of 1 per 264 births was consistent with the expected prevalence of 1 in 250 . Of the 2359 pregnancies, 37 were twin pregnancies and two were triplet pregnancies, resulting in 2400 offspring. Table 1 gives a description of the outcomes according to gestation at delivery.

\section{Maternal characteristics}

More than a quarter of the pregnancies were to women with type 2 diabetes $(\mathrm{n}=652 ; 27.6 \%)$. Table 2 shows the characteristics of the women according to type of diabetes. Compared with the women with type 1 diabetes, women with type 2 diabetes were older at onset of diabetes $(\mathrm{P}<0.001)$ and at delivery $(\mathrm{P}<0.001)$, less likely to be primigravid $(\mathrm{P}<0.001)$, and more likely to live in a deprived area $(\mathrm{P}<0.001)$ and to come from a Black, Asian, or other ethnic minority group $(\mathrm{P}<0.001)$. The biggest difference in the prevalence of the two types of diabetes was observed in women of Pakistani origin (type 2 diabetes 16\%; type 1 diabetes $1.4 \%)$.

Most women $(1606 ; 68 \%)$ had a recorded measurement of glycaemic control by 13 weeks of pregnancy. Good control, defined by glycated haemoglobin $\left(\mathrm{HbA}_{1 c}\right)$ of less than $7 \%$, was achieved by $596(37 \%)$ women. The median $\mathrm{HbA}_{1 c}$ was $7.9 \%$ for the women whose pregnancies resulted in a congenital anomaly, $8.0 \%$ for those with a normally formed stillbirth or neonatal

Table 2 Maternal characteristics by type of diabetes. Values are numbers (percentages) unless stated otherwise

\begin{tabular}{lcc} 
& $\begin{array}{c}\text { Women with type 1 } \\
\text { diabetes (n=1707) }\end{array}$ & $\begin{array}{c}\text { Women with type 2 } \\
\text { diabetes (n=652) }\end{array}$ \\
\hline $\begin{array}{l}\text { Median (IQR) age (years) at onset of } \\
\text { diabetes }\end{array}$ & $15(9-23)$ & $29(25-34)$ \\
\hline Median (IQR) age (years) at delivery & $30(26-34)$ & $34(30-37)$ \\
\hline Ethnicity: & $1549(90.7)$ & $331(50.8)$ \\
\hline White & $23(1.4)$ & $47(7.2)$ \\
\hline Black African & $27(1.6)$ & $33(5.1)$ \\
\hline Black Caribbean & $4(0.2)$ & $3(0.5)$ \\
\hline Black other & $25(1.5)$ & $47(7.2)$ \\
\hline Indian & $24(1.4)$ & $106(16.3)$ \\
\hline Pakistani & $7(0.4)$ & $47(7.2)$ \\
\hline Bangladeshi & $1(0.1)$ & $2(0.3)$ \\
\hline Chinese & $45(2.6)$ & $33(5.1)$ \\
\hline Other & $2(0.1)$ & $3(0.5)$ \\
\hline Not known & $925(54.2)$ & $495(75.9)$ \\
\hline Multiparous & $260(16.7)$ & $40(6.4)$ \\
\hline Deprivation fifth*: & $288(18.5)$ & $66(10.5)$ \\
\hline 1 (least deprived) & $313(20.1)$ & $81(12.9)$ \\
\hline 2 & $307(19.7)$ & $145(23.1)$ \\
\hline 3 & $355(22.8)$ & $291(46.3)$ \\
\hline 4 & $35(2.2)$ & $5(0.8)$ \\
\hline 5 (most deprived) & 149 & 24 \\
\hline Not known & & \\
\hline Resident in Wales or Northern Ireland & & \\
\hline
\end{tabular}

$\mathrm{IQR}=$ interquartile range.

*Percentages calculated only for women resident in England. 
Table 3 Crude stillbirth rate and perinatal and neonatal mortality in births to women with type 1 or type 2 diabetes

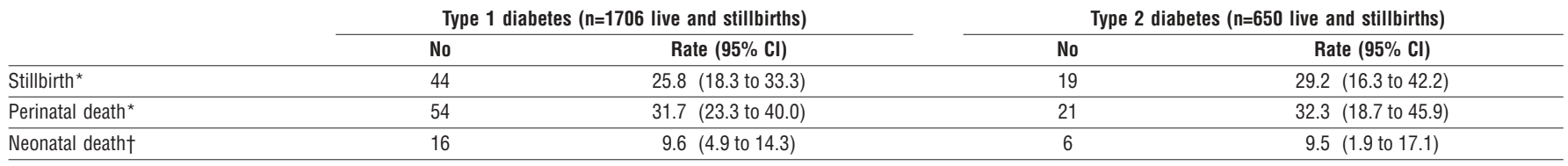

Figures do not include 13 terminations of pregnancy (9 type 1, 4 type 2) before 20 weeks' gestation and 31 losses (22 type 1, 9 type 2 ) between 20 weeks' and $23^{+6}$ weeks' gestation. ${ }^{*}$ Rate per 1000 live births plus stillbirths.

†Rate per 1000 live births.

death, and 7.4\% for those who had a normally formed baby alive at day 28.

\section{Perinatal mortality}

During the study, 63 stillbirths and 22 neonatal deaths occurred. Two neonatal deaths occurred before 24 weeks' gestation, and one neonatal death was a termination occurring between 24 and 27 weeks' gestation. Table 3 shows the crude stillbirth rates and perinatal and neonatal mortality according to type of diabetes. Figures adjusted for maternal age show significantly higher stillbirth rates (4.7 times higher) and perinatal (3.8 times) and neonatal mortality (2.6 times) in this cohort compared with the general maternity population in 2002 (table 4 ).

Of the 63 stillbirths, 52 had no congenital anomaly (table 1). In terms of weight adjusted for gestation at delivery, parity of mother, and sex of baby, a higher proportion of singleton normally formed stillbirths were above the 90th centile (18/31 (58.1\%) compared with $1061 / 2058(51.6 \%)$ of normally formed singleton babies alive at day 28. This difference was not statistically significant. The proportion of babies below the 10th centile was similar-1/31 (3.2\%) normally formed singleton stillbirths and 58/2058 (2.8\%) normally formed singleton babies alive at day 28.

\section{Congenital anomalies}

A total of 141 major congenital anomalies were identified and confirmed in 109 offspring (table 5). The number of offspring with more than one major anomaly was 23 (21.1\% of offspring with anomalies). The most common diagnoses were multiple anomalies of the heart or of the limb, musculoskeletal, and connective tissue system.

The prevalence of major anomalies in the offspring was 46 per 1000 total births. This compares with 21 per 1000 total births from the EUROCAT data for 2002 (prevalence ratio 2.2, 95\% confidence interval 1.8 to $2.6 ; \mathrm{P}<0.001)$. The prevalence of major anomalies associated with type 1 diabetes was 48 per 1000 total births, and the prevalence associated with type 2 diabetes was 43 per 1000 total births.

Statistically significant increases were confined to anomalies of the nervous system (prevalence ratio $2.7,1.5$ to $4.4 ; \mathrm{P}<0.001$ ) and congenital heart disease (prevalence ratio $3.4,2.5$ to 4.6 ; $\mathrm{P}<0.001)$. The increase in anomalies of the nervous system was

Table 4 Maternal age adjusted stillbirth rate and perinatal and neonatal mortality in births to women with type 1 and type 2 diabetes compared with national data.

\begin{tabular}{|c|c|c|c|c|}
\hline & \multicolumn{2}{|c|}{$\begin{array}{l}\text { Type } 1 \text { and } 2 \text { diabetes ( } \mathrm{n}=2356 \\
\text { live and stillbirths) }\end{array}$} & \multirow{2}{*}{$\begin{array}{c}\text { National } \\
\text { rate }^{*}(n=620 \\
841)\end{array}$} & \multirow{2}{*}{$\begin{array}{l}\text { Rate ratio }(95 \% \\
\text { CI) }\end{array}$} \\
\hline & Number & Rate $(95 \% \mathrm{CI})$ & & \\
\hline Stillbirth† & 63 & 26.8 (19.8 to 33.8 ) & 5.7 & 4.7 (3.7 to 6.0$)$ \\
\hline Perinatal death† & 75 & 31.8 (24.2 to 39.4 ) & 8.5 & 3.8 (3.0 to 4.7$)$ \\
\hline Neonatal death $\ddagger$ & 22 & 9.3 (5.2 to 13.3$)$ & 3.6 & 2.6 (1.7 to 3.9$)$ \\
\hline
\end{tabular}

${ }^{*}$ Source for national data: CEMACH 2002. ${ }^{10}$

†Rate per 1000 live births plus stillbirths.

tRate per 1000 live births. driven by an increase in the observed number of neural tube defects (prevalence ratio 4.2, 2.0 to $7.8 ; \mathrm{P}<0.001$ ). The ratio for neural tube defects determined from the EUROCAT data from Wales and England only was 3.3 (1.6 to $6.1 ; \mathrm{P}<0.001)$. The neural tube defects were diagnosed antenatally in all 10 offspring.

Anomalies in 71 (65\%) of 109 offspring with anomalies were diagnosed antenatally $(23 / 42(54.8 \%)$ of offspring with congenital heart disease and 48/67 (71.6\%) of offspring with anomalies other than congenital heart disease) (table 6). Fifty per cent (35/ 71) of the anomalies diagnosed antenatally were terminated (table 1).

\section{Discussion}

This large national study details the outcomes of pregnancy for women with type 1 or type 2 diabetes. Nearly 15 years on from the St Vincent declaration,,$^{15}$ women with diabetes in England, Wales, and Northern Ireland continue to have high perinatal

Table 5 Observed (and expected ${ }^{\star}$ ) anomalies reported in 2400 offspring to women with diabetes

\begin{tabular}{lcccc} 
Anomalies & $\begin{array}{c}\text { Offspring of } \\
\text { women with } \\
\text { type 1 diabetes }\end{array}$ & $\begin{array}{c}\text { Offspring of } \\
\text { women with } \\
\text { type 2 } \\
\text { diabetes }\end{array}$ & Total & $\begin{array}{c}\text { Standardised } \\
\text { prevalence ratio } \\
\text { (95\% Cl) }\end{array}$ \\
\hline $\begin{array}{c}\text { One or more major } \\
\text { anomalies of any } \\
\text { type }\end{array}$ & $81(37.0)$ & $28(12.8)$ & $109(49.8)$ & 2.2 (1.8 to 2.6) \\
\hline
\end{tabular}

$$
\text { type }
$$

\begin{tabular}{llllll}
\hline Anomaly system $\dagger$ \\
\hline Nervous system: & $11(4.1)$ & $4(1.5)$ & $15(5.6)$ & 2.7 (1.5 to 4.4) \\
\hline $\begin{array}{l}\text { Neural tube } \\
\text { defects }\end{array}$ & $6(2.4)$ & $4(0.9)$ & $10(2.4)$ & 4.2 (2.0 to 7.8)
\end{tabular}

\begin{tabular}{llllll}
\hline Remainder of CNS & $5(1.7)$ & $0(0.6)$ & $5(3.0)$ & $1.5(0.3$ to 3.6) \\
\hline Eye & $1(2.4)$ & $0(0.9)$ & $1(1.0)$ & $1.0(0.1$ to 7.0$)$ \\
\hline
\end{tabular}

\begin{tabular}{lccccc}
\hline Ear & $0(0.7)$ & $0(0.3)$ & $0(1.0)$ & - \\
\hline $\begin{array}{l}\text { Congenital heart } \\
\text { disease }\end{array}$ & $33(8.9)$ & $9(3.4)$ & $42(12.3)$ & 3.4 (2.5 to 4.6) \\
\hline
\end{tabular}

\begin{tabular}{llllll}
\hline Cleft lip \pm palate & $0(1.3)$ & $0(0.5)$ & $0(1.8)$ & - \\
\hline Cleft palate & $2(0.9)$ & $0(0.3)$ & $2(1.2)$ & $1.6(0.2$ to 5.9) \\
\hline Digestive system & $1(2.6)$ & $2(1.0)$ & $3(3.5)$ & $0.8(0.2$ to 2.5) \\
\hline
\end{tabular}

\begin{tabular}{llllll} 
Digestive system & $1(2.6)$ & $2(1.0)$ & $3(3.5)$ & $0.8(0.2$ to 2.5$)$ \\
\hline Internal urogenital & $9(6.1)$ & $1(2.3)$ & $10(8.5)$ & $1.2(0.6$ to 2.2$)$
\end{tabular}
system

\begin{tabular}{lcccc}
$\begin{array}{l}\text { External genital } \\
\text { system }\end{array}$ & $3(2.5)$ & $2(0.9)$ & $5(3.4)$ & 1.5 (0.5 to 3.4) \\
\hline $\begin{array}{l}\text { Limb, } \\
\text { musculoskeletal, } \\
\text { and connective } \\
\text { tissue }\end{array}$ & $15(10.2)$ & $4(3.7)$ & $19(13.9)$ & 1.4 (0.8 to 2.1) \\
\hline $\begin{array}{l}\text { Other } \\
\text { non-chromosomal }\end{array}$ & 6 & 4 & 10 & - \\
\hline Chromosomal: & $4(7.2)$ & $2(4.2)$ & $6(11.4)$ & $0.5(0.2$ to 1.1) \\
\hline Trisomy 21 & 2 & 0 & 2 & - \\
\hline $\begin{array}{l}\text { Other } \\
\text { chromosomal }\end{array}$ & 2 & 2 & 4 & - \\
\hline
\end{tabular}

CNS=central nervous system.

*Expected numbers in parentheses based on data from EUROCAT 2002, adjusted for maternal age.

†Multiple anomalies within groups counted only once; total anomalies thus do not add up to 141. 
Table 6 Timing of diagnosis and description of the principal anomaly in 109 offspring with major anomaly

\begin{tabular}{|c|c|c|c|}
\hline Anomalies & $\begin{array}{l}\text { Antenatally } \\
\text { diagnosed } \\
\text { (No) }\end{array}$ & $\begin{array}{l}\text { Postnatally } \\
\text { diagnosed } \\
\text { (No) }\end{array}$ & Total (No) \\
\hline Cardiac anomalies: & 23 & 19 & \multirow{14}{*}{42} \\
\hline Atrioseptal defect & - & 2 & \\
\hline Hypoplastic left heart & 5 & - & \\
\hline Ventricular septal defect & 1 & 4 & \\
\hline Double inlet left ventricle & 1 & - & \\
\hline Double outlet right ventricle & 2 & - & \\
\hline Transposition of great arteries & 1 & 3 & \\
\hline Pulmonary artery stenosis & 2 & 2 & \\
\hline $\begin{array}{l}\text { Pulmonary artery atresia with intact } \\
\text { ventricular septum }\end{array}$ & 1 & - & \\
\hline Tetralogy of Fallot & 3 & 4 & \\
\hline Coarctation of aorta & 1 & 1 & \\
\hline Total pulmonary abnormal venous return & - & 1 & \\
\hline Other* & 3 & 1 & \\
\hline Unspecified/misclassified & 3 & 1 & \\
\hline Limb, musculoskeletal, and connective tissue: & 15 & 2 & \multirow{9}{*}{17} \\
\hline Caudal regression & 4 & 1 & \\
\hline Diaphragmatic hernia & 2 & - & \\
\hline Gastroschisis & 2 & - & \\
\hline Achondroplasia & 1 & - & \\
\hline Other limb defects & 1 & - & \\
\hline Scoliosis & 1 & - & \\
\hline Prune belly syndrome & 1 & - & \\
\hline Other anomalies & 3 & 1 & \\
\hline Nervous system: & 13 & 2 & \multirow{3}{*}{15} \\
\hline Neural tube defects & 10 & 0 & \\
\hline Other central nervous system & 3 & 2 & \\
\hline Eye & - & 1 & 1 \\
\hline Internal urogenital system & 8 & 1 & 9 \\
\hline External genital system & - & 4 & 4 \\
\hline Chromosomal & 6 & - & 6 \\
\hline Others, non-chromosomal & 6 & 4 & 10 \\
\hline Digestive system & - & 3 & 3 \\
\hline Cleft palate & - & 2 & 2 \\
\hline Overall & 71 & 38 & 109 \\
\hline
\end{tabular}

*Ebstein anomaly, isomerism of atrial appendages, malformation of pulmonary artery and of aorta.

mortality rates (31.8/1000 births), three times greater than for the general maternity population. Perinatal mortality in European countries and in other UK regional studies of outcomes of pregnancy for women with diabetes range from 27.8 to 48 per 1000 births. $^{1-4} 781617$

At the time of the St Vincent declaration evidence existed to show that near normal metabolic control before and around conception reduced anomaly rates in the pregnancies of women with diabetes, ${ }^{18}{ }^{19}$ and by 1996 this was reinforced by the diabetes control and complications trial. ${ }^{20}$ Since then guidance has been issued on this topic, ${ }^{21}$ but little success has been achieved in translating this into practice. Only $37 \%$ of women with a recorded $\mathrm{HbA}_{1 \mathrm{c}}$ test achieved good glycaemic control by the end of the first trimester. This does not compare well with the Netherlands, where $75 \%$ of women with type 1 diabetes achieved $\mathrm{HbA}_{\mathrm{lc}}$ of $7 \%$ or less in the first trimester. ${ }^{1}$ We did our study at the same time as the national service framework for diabetes delivery strategy was released, ${ }^{5}$ and the results will be a reference point from which to judge the effectiveness of the framework in tackling this public health concern.

\section{Congenital anomalies}

The risk of major congenital anomalies in the offspring of women with diabetes was more than twice that of the general population. Other studies have shown comparable prevalence figures for congenital anomalies, ranging from 41 per 1000 to 97 per 1000, although these studies have been based predominantly on the babies of women with type 1 diabetes. ${ }^{1-3} 7816{ }^{17}$ Comparisons are limited because of differences in inclusion criteria for minor anomalies and early pregnancy outcomes.

In our study, the increased risk of anomalies was predominantly for congenital heart disease (3.4 times higher risk) and anomalies of the nervous system (2.7 times higher risk). In particular, the risk of neural tube defects was three to four times higher than expected. The minimum effective dose of folic acid needed to reduce this risk is not established, but because of the increased risk, women with diabetes should take a higher than usual dose $(5 \mathrm{mg}$ ) from before conception up to week 12 of pregnancy. ${ }^{51}$

Antenatal diagnosis of some cardiac conditions decreases the risk of neonatal mortality. ${ }^{22}$ Routine ultrasound scanning for anomalies in the UK has been reported to identify $23 \%$ of cardiac defects. ${ }^{23}$ Implementing specialist views of the fetal heart may increase the pick-up rate of cardiac anomalies up to $75 \%{ }^{24}$ Our study showed that cardiac lesions were the most frequent anomaly in the offspring of women with diabetes, and $55 \%$ were detected antenatally. Current management of pregnant women with diabetes in the UK does not routinely include targeted screening for cardiac defects; this needs to be reviewed.

\section{Type 2 diabetes}

In the past decade, type 2 diabetes in pregnancy has emerged as a growing concern. ${ }^{25}$ Few population studies have provided perinatal mortality and congenital anomaly rates in women with type 2 diabetes diagnosed before pregnancy. Two of the largest such studies were based on Maori women in New Zealand and Hispanic women in California and may not be generalisable. ${ }^{26}{ }^{27}$ Other studies have included women in whom the diagnosis of type 2 diabetes was not made until after delivery. ${ }^{26-30}$ Reported perinatal mortality in these studies ranges from 6 per 1000 to 313 per 1000 births. $^{28} 30$

Our study is larger than previous studies describing pregnancy outcomes for women with type 2 diabetes diagnosed before pregnancy and shows that adverse pregnancy outcomes for these women are comparable to those for women with type 1 diabetes. Several studies have reported higher perinatal mortality and congenital anomaly rates in the babies of women with type 2 diabetes than in the babies of women with type 1 diabetes, but they were based on relatively small sample sizes. ${ }^{26}{ }^{29}{ }^{31-33}$ Our study shows no evidence of an increased risk. However, even a study of this magnitude was underpowered to detect a significant increase of less than $25 \%$ for perinatal mortality and of less than $80 \%$ for congenital anomaly, if such increases were present. We conclude that no evidence exists of major differences in the risks of perinatal mortality and congenital anomaly in the offspring of women with type 1 and type 2 diabetes.

Pregnant women with type 2 diabetes were more likely to live in a deprived area $(\mathrm{P}<0.001)$ or come from an ethnic minority background $(\mathrm{P}<0.001)$. These factors may be interrelated. Women with type 2 diabetes often need to change their treatment to insulin before or during pregnancy. The differences in cultural background, first language, lifestyle, and medical care need to be accounted for when considering provision of health services for preconception care and education in this area. In the past, type 2 diabetes may have been viewed as a less serious condition than type 1 diabetes and may have been subject to less vigilant care. ${ }^{34}$ In view of the increasing prevalence of type 2 dia- 
betes in young adults, raised awareness of the increased risk of adverse pregnancy outcomes in this group of women is needed.

\section{Conclusion}

Women with type 1 diabetes and those with type 2 diabetes both represent high risk groups during pregnancy. As the incidence of diagnosed diabetes continues to increase, especially at young ages, the number of women with diabetes in pregnancy will also continue to increase. Our study found a threefold increase in perinatal mortality and a twofold increase in the congenital anomaly rate in women with diabetes compared with the general maternity population. Despite evidence since the late 1980s that good glycaemic control around conception and early pregnancy can reduce these adverse outcomes, minimal improvement seems to have occurred, and only a minority of women achieve good periconceptional glycaemic control.

This study is substantially larger than any previous ones in describing pregnancy outcomes for women with pre-gestational type 2 diabetes. It shows that perinatal mortality and congenital anomaly rates are comparable to those for type 1 diabetes. More work is needed to elucidate how women with either type of diabetes can best be enabled to improve the outcomes of their pregnancy.

We thank all the health professionals who were involved in the data collection at unit level; CEMACH regional managers and assistants for collecting and validating the data; Marjorie Renwick of the Northern Regional Maternity Survey Office for reviewing and coding all the suspected anomalies; EUROCAT for providing age specific congenital anomalies rates; and members of the CEMACH Diabetes Professional Advisory Group for their continued advice and guidance.

Contributors: MCMM, KMF, and JAB developed the idea for the paper and drafted the paper. MCMM and JM designed the study. JAB, KMF, and PD did the statistical analysis. AM and SG were involved in collecting the data. DA categorised the cardiac anomalies. PD, JM, DA, SG, and AM advised on interpretation of the results. All authors revised the paper critically and approved the final manuscript. MCMM is the guarantor.

Funding: CEMACH was funded by the National Institute for Clinical Excellence until 31 March 2005, by the National Patient Safety Agency from 1 April 2005, and by the Department of Health, Social Services and Public Safety of Northern Ireland.

Competing interests: None declared.

Ethical approval: As this programme was part of a national clinical audit, ethical approval and consent were not specifically sought. CEMACH obtained section 60 approval (under the Health and Social Care Act) for its programmes in December 2003.

1 Evers IM, de Valk HW, Visser GHA. Risk of complications of pregnancy in women with type 1 diabetes: nationwide prospective study in the Netherlands. BMJ 2004;328:915-9.

\section{What is already known on this topic}

Babies born to women with diabetes are known to have increased risks of perinatal mortality and congenital anomalies; most studies have focused on type 1 diabetes

Type 2 diabetes is being diagnosed in an increasing number of women of childbearing age in the UK

\section{What this study adds}

The increased risk of anomalies is predominantly accounted for by congenital heart disease and neural tube anomalies

Risks of perinatal mortality and congenital anomalies in the offspring of women with pre-gestational type 2 diabetes are equivalent to those in the offspring of women with type 1 diabetes
2 Jensen DM, Damm P, Moelsted-Pedersen L, Ovensen P, Westergaard JG, Moeller M, et al. Outcomes in type 1 diabetic pregnancies. Diabetes Care 2004;27:2819-23.

3 Suhonen L, Hiilesmaa V, Teramo K. Glycaemic control during early pregnancy and fetal anomalies in women with type 1 diabetes mellitus. Diabetologia 2000;43:79-82.

4 Penney GC, Mair G, Pearson DW. Outcomes of pregnancies in women with type 1 diabetes in Scotland: a national population based study. Br J Obstet Gynaecol 2003;110:315-8

5 Department of Health. National service framework for diabetes (England) standards. London: Stationery Office, 2001.

6 Hotu S, Carter B, Watson PD, Cutfield WS, Cundy T. Increasing prevalence of type 2 diabetes in adolescents J Paediatr Child Health 2004;40:201-4.

7 Casson IF, Clarke CA, Howard CV, McKendrick O, Pharoah POD, Platt MJ. Outcomes of pregnancy in insulin dependent diabetic women: results of a five year population cohort study. BMJ 1997;315:275-8.

8 Hawthorne G, Robson S, Ryall EA, Roberts SH, Ward Platt MP. Prospective population based survey of outcome of pregnancy in diabetic women: results of the Northern Diabetic Pregnancy Audit, 1994. BMJ 1997;315:279-81.

9 Confidential Enquiry into Maternal and Child Health. Pregnancy in women with type 1 and type 2 diabetes in 2002-3. London: CEMACH, 2005.

10 Confidential Enquiry into Maternal and Child Health. Maternity Services in 2002 for women with type 1 and type 2 diabetes, England, Wales and Northern Ireland. London: RCOG Press, 2004.

11 Office for the Deputy Prime Minister. Index of multiple deprivation 2004. www.communities.gov.uk/index.asp?id = 1128440 (accessed 1 June 2006).

12 Confidential Enquiry into Maternal and Child Health. Stillbirth, neonatal and post-neonatal mortality 2000-2003, England, Wales and Northern Ireland. London: RCOG Press, 2005.

13 European Registration of Congenital Anomalies. Report 8: surveillance of congenital anomalies in Europe 1980-1999. EUROCAT Central Registry: Newtownabbey, County Antrim, 2002.

14 Bailar JC, Ederer F. Significance factors for the ratio of a Poissson variable to its expectation. Biometrics 1964;20:639-43.

15 Workshop Report. Diabetes care and research in Europe: the Saint Vincent declaration. Diabet Med 1990:7:360.

16 Platt MJ, Stanisstreet M, Casson IF, Howard CV, Walkinshaw S, Pennycook S, et al. St Vincent's declaration 10 years on: outcomes of diabetic pregnancies. Diabet Med 2002;19:216-20.

17 Diabetes and Pregnancy Group. French multicentric survey of outcome of pregnancy in women with pregestational diabetes. Diabetes Care 2003;26:2990-3.

18 Fuhrmann K, Reiher H, Semmler K, Glockner E. The effect of intensified conventional insulin therapy before and during pregnancy on the anomaly rate of offspring of diabetic mothers. Exp Clin Endocrinol 1984;83:173-7.

19 Damm P, Molsted-Pedersen L. Significant decrease in congenital anomalies in newborn infants of an unselected population of diabetic mothers. Am J Obstet Gynecol 1989;161:1161-7.

20 Diabetes Control and Complications Trial Research Group. Pregnancy outcomes in the diabetes control and complications trial. Am J Obstet Gynecol 1996;174:1343-53.

21 Scottish Intercollegiate Guidelines Network. Management of diabetes in pregnancy. Edinburgh: SIGN, 2001. (SIGN publication No 55, updated from No 9 (1996).)

22 Khoshnood B, De Vigan C, Vodovar V, Goujard J, Lhomme A, Bonnet D, et al. Trends in prenatal diagnosis, pregnancy termination, and perinatal mortality of newborns with congenital heart disease in France, 1983-2000: a population-based evaluation. Pediatrics 2005;115:95-101.

23 Bull C. Current and potential impact of fetal diagnosis on prevalence and spectrum of serious congenital heart disease at term in the UK. Lancet 1999;354:1242-7.

24 Carvalho JS, Mavrides E, Shinebourne EA, Campbell S, Thilaganathan B. Improving the effectiveness of routine prenatal screening for major congenital heart defects. Heart 2002;88:387-91.

25 Feig DS, Palda VA. Type 2 diabetes in pregnancy: a growing concern. Lancet 2002:359:1690-2.

26 Cundy T, Gamble G, Townend K, Henley PG, MacPherson P, Roberts AB. Perinatal mortality in type 2 diabetes mellitus Diabet Med 2000;17:33-9.

27 Towner D, Kjos SL, Leung B, Montoro MM, Xiang A, Mestman JH, et al. Congenital anomalies in pregnancies complicated by NIDDM. Diabetes Care 1995;18:1446-51.

28 Coetzee EJ, Jackson WP. The management of non-insulin dependent diabetes during pregnancy. Diabetes Res Clin Pract 1985-86;1:281-7.

29 Sacks DA, Chen W, Greenspoon JS, Wolde-Tsadik G. Should the same glucose values be targeted for type 1 as for type 2 diabetics in pregnancy? Am J Obstet Gynecol 1997:177:1113-9

30 Zhu L, Makabayashi M, Takeda Y. Statistical analysis of perinatal outcomes in pregnancy complicated with diabetes mellitus. J Obstet Gyneacol Res 1997;23:555-63.

31 Brydon P, Smith T, Proffitt M, Gee H, Holder R, Dunne F. Pregnancy outcome in women with type 2 diabetes mellitus needs to be addressed. Int I Clin Pract 2000;54:418-9.

32 Dunne F, Brydon P, Smith K, Gee H. Pregnancy in women with type 2 diabetes: 12 year outcome data 1990-2002. Diabet Med 2003;20:734-8.

33 Clausen TD, Mathiesen E, Ekbom P, Hellmuth E, Mandrup-Poulsen T, Damm P. Poor pregnancy outcome in women with type 2 diabetes. Diabetes Care 2005;28:323-8.

34 Dunne F. Type 2 diabetes and pregnancy. Semin Fetal Neonatal Med 2005;10:333-40.

(Accepted 14 April 2006)

doi 10.1136/bmj.38856.692986.AE

Confidential Enquiry into Maternal and Child Health, London NW1 5SD

Mary C M Macintosh medical director

Kate M Fleming senior data analyst

Jaron A Bailey health research data analyst

Jo Modder obstetric lead

Dominique Acolet neonatal lead

Shona Golightly director of research and development 
Alison Miller programme director

London School of Hygiene and Tropical Medicine, London WC1E 7HT
Pat Doyle reader in epidemiology

Correspondence to: M Macintosh mary.macintosh@hpa.org.uk

8

ర్ల 